\title{
Obstetrical Acute Kidney Injury: Epidemiology and Clinical Aspects in Teaching Hospital of Ignace Deen, Conakry Guinea
}

\author{
Ibrahima Koussy Bah'1, Fousseny Diakite ${ }^{2 *}$, Mamadou Saliou Baldé2, Abdouramane Diallo1, \\ Mamadou Yacine Bah', Amadou Yaya Diallo², Alpha Boubacar Bah², Moussa Traore², \\ Telly Sy Diallo ${ }^{1}$, Alpha Oumar $\mathrm{BaH}^{2}$
}

${ }^{1}$ Unit of Gyneco-Obstetric of the National Hospital Ignace Deen, Conakry, Guinea

${ }^{2}$ Unit of Nephrology-Hemodialysis of the National Hospital Donka, Conakry, Guinea

Email: ^fdiak70@gmail.com

How to cite this paper: Bah, I.K., Diakite, F., Baldé, M.S., Diallo, A., Bah, M.Y., Diallo, A.Y., Bah, A.B., Traore, M., Diallo, T.S. and BaH, A.O. (2020) Obstetrical Acute Kidney Injury: Epidemiology and Clinical Aspects in Teaching Hospital of Ignace Deen, Conakry Guinea. Case Reports in Clinical Medicine, 9, 35-39.

https://doi.org/10.4236/crcm.2020.91006

Received: October 30, 2019

Accepted: January 7, 2020

Published: January 10, 2020

Copyright $\odot 2020$ by author(s) and Scientific Research Publishing Inc. This work is licensed under the Creative Commons Attribution International License (CC BY 4.0).

http://creativecommons.org/licenses/by/4.0/

\begin{abstract}
Introduction: In Guinea, data on the acute kidney injury (AKI) of women in the obstetrical context is still limited. This study attempted to determine the prevalence and the clinical signs of obstetric AKI in Guinea. Patients and methods: The study population consisted of pregnant or postpartum women with AKI, whom we treated in this institute from August 2018 to January 2019. All had normal anterior renal function with serum creatinine clearance $\geq 120 \mu \mathrm{mol} / \mathrm{L}$, and then suffered AKI. Patients characteristics were examined; maternal age, gestational weeks, AKI characteristics. Results: Of 2438 pregnant women admitted during the study period, 56 showed AKI. Antepartum and postpartum AKI accounted for approximately $80 \%$ and $17 \%$, respectively. Regarding the maternal age, $<25$ years of age accounted for $54 \%$ (range: 17 40). Multiple gestations accounted for 34 (60.71\%) of which functional AKI, organic AKI, and obstructive AKI accounted for 28/34, 2/34, and 4/34, respectively. Regarding the clinical manifestations, abdominal pain, tinnitus, visual disturbances, edema of the lower limb, and facial swelling accounted for $79 \%, 75 \%, 7 \%, 57 \%$, and 54\%, respectively. Conclusion: We here demonstrated peripartum AKI in Guinea, which findings may provide fundamental data to establish some strategy against this condition in this region.
\end{abstract}

\section{Keywords}

Obstetric AKI, Epidemiological and Clinical Aspects, Ignace Deen Conakry

\section{Introduction}

Acute renal insufficiency is defined as a sudden and temporary decrease in renal 
function during pregnancy or during the peripartum period [1] [2].

It is a serious and formidable complication in obstetric settings. It is one of the major causes of morbidity and maternal-fetal mortality [1] [2].

Pregnancy-related ARI can be induced by the same causes as in the general population (functional, parenchymal, obstructive and septic causes) [3] but is more frequently related to specific pathologies of pregnancy with a different chronological distribution function of the term of pregnancy [4].

In Guinea, studies of women's AKI in obstetric settings are still under-explored. The objective of our work was to determine the prevalence of obstetric AKI and to describe the clinical manifestations observed in parturients.

\section{Patients and Methods}

This was a prospective study of the descriptive type over a 6-month period from 1 August 2018 to 31 January 2019. Included in this study all pregnant or immediate postpartum women hospitalized and/or followed in the hospital that had normal anterior renal function and serum creatinine $\geq 120 \mu \mathrm{mol} / \mathrm{l}$.

Our variables were: age, gestational, paraclinical and type of kidney insufficiency.

The diagnosis of ARI was selected on the basis of Creatinine level greater than or equal to $120 \mu \mathrm{mol} / \mathrm{l}$ and ultrasound which showed normal size kidneys with good corticomedullary differentiation. Also absent were renal osteodystrophy hypocalcemia and normochromic and normocytic arterial anemia. The AKI was functional in a clinical context of dehydration, oliguria; urine too dark.

The ARI was organic in the presence of elevated serum creatinine for more than 7 days with preserved or unreserved diuresis on the urinary excretory tract. The repeated control of serum creatinine allowed us to follow the evolution of the patients. This was defined according to the following modalities: The recovery was complete if the resumption of normal renal function was effective in $100 \%$ of cases. Creatinine levels returned to normal during treatment during hospitalization.

Classification of acute renal failure according to the classification of RIFLE [5].

\section{Results}

During the period, we admitted 2438 parturients, of whom 56 were included. All parturients had a serum creatinine greater than $120 \mu \mathrm{mol} / 1$ and $75 \%$ of them had microcytic anemia of between 8 and $10 \mathrm{~g} / \mathrm{dl}$. Calcium was normal in all 56 parturients. The course was marked by a normal recovery of the renal function in 54 parturients $(96.42 \%)$, a chronic renal insufficiency in 02 parturients whose renal function did not normalize during the duration of follow-up. One of them died in hemodialysis. Three cases of fetal death have been recorded.

$26.11 \pm 6$ years with extremes of 17 and 40 years.

\section{Discussion}

During our study, we collected 2438 patients who came for consultation, of which 56 developed an obstetric AKI, a frequency of $2.29 \%$. 
Statistical data from developing countries show that the incidence of obstetric AKI is: in India, Pakistan and Africa 7\% - 11\%, 18\% and 57\% respectively [6].

In Senegal, Diouf A.A. and Coll. in an obstetric gynecology ward in Dakar, found $8 \%$ of obstetrical AKI [7].

This low rate in our study could be explained by the high sample size and the duration of the study.

More than $80 \%$ of parturients had antepartum AKI and $17 \%$ postpartum AKI.

Parturients under 25 were the most frequent, 53.57\%. The average age was $26.11 \pm 6$ years with extremes of 17 and 40 years (Table 1 ).

This result is close to that found by S. Alaoui et al. [8] in Morocco in 2016 who reported an average age of $29 \pm 6$ years. On the other hand, it is different from that of A.T. Lemrabott et al. [9] who reported in their study an average age of $32 \pm 6$ years.

According to the types of AKI we had functional AKI, organic AKI and obstructive AKI $62.5 \%, 28.6 \%$, and $9.9 \%$ respecty (Table 2 ). The pregnancy-related ARI can be induced by the same causes as in the general population (functional, parenchymal, obstructive and septic causes) [3] but it is more frequently linked to specific pathologies of pregnancy with a different chronological distribution depending on the term of pregnancy [4]. These observations reinforce our findings that all types of ARI are observed.

In our study, multiple gestures accounted for $60.72 \%$ (34/56), including 28/34 functional AKI cases, 2/34 organic AKI cases, and 4/34 obstructive AKI cases.

Our result is different from that of Eswarappa et al. [10] in India in 2016 who found in their study a frequency of $52 \%$ primigest.

The main clinical manifestations were dominated by abdominal pain with $78.57 \%$, tinnitus with $75 \%$, visual disturbances with $7.43 \%$, edema of the lower limbs with $57.14 \%$ and facial swelling with $53.57 \%$ (Table 3 ). The clinical picture in M.M.T. Zeinabou et al. [11] was dominated on admission by $40.6 \%$ of cases of oliguria, $37.5 \%$ of cases of edema and $37.5 \%$ of cases of seizure, $3.12 \%$ of cases of anuria.

According to the RIFLE classification, the stage E of the AKI was the most represented, $39.29 \%$ of the cases followed by stage I and R respectively in $21.43 \%$ and $17.86 \%$ (Table 4). this result is different from that obtained by S. Alaoui et al. [8] in Morocco in 2016 reported in their study $35.4 \%$ at stage $\mathrm{R}$ followed by $26.2 \%$ at stage I and $38.5 \%$ at stage $\mathrm{F}$.

Table 1. Socio-demographic parameter.

\begin{tabular}{cccc}
\hline \multicolumn{2}{c}{ Parameter } & Number & $\%$ \\
\hline \multirow{2}{*}{ Fréquency } & AKI anté-partum & 46 & 82.14 \\
& AKI post-partum & 10 & 17.86 \\
& Age (year) & 56 & 100 \\
$16-25$ & 30 & 53.57 \\
$26-35$ & 20 & 35.71 \\
$35-45$ & 6 & 10.72
\end{tabular}


Table 2. AKI and gestation.

\begin{tabular}{ccccc}
\hline Gestity & Fonctional AKI & Parenchyma AKI & Obstructive AKI & Total \\
\hline Multipare & 28 & 2 & 4 & 34 \\
Paucipara & 3 & 10 & 1 & 14 \\
Primipara & 4 & 4 & 0 & 8 \\
Total & 35 & 16 & 5 & 56 \\
\hline
\end{tabular}

Table 3. Clinical Sign in admission.

\begin{tabular}{ccc}
\hline Clinical Sign & Number & Percentage \\
\hline Abdominal pain & 44 & 78.57 \\
Visual disturbance & 40 & 71.43 \\
Hearing loss & 42 & 75.00 \\
CEdèma Foot & 32 & 57.14 \\
Swelling & 30 & 53.57 \\
Nausea/Vomit & 35 & 62.5 \\
Confusion & 6 & 10.71 \\
Oligo-anuria & 4 & 7.14 \\
Diarrhea & 2 & 3.57 \\
\hline
\end{tabular}

Table 4. RIFLE Classification of patient.

\begin{tabular}{ccc}
\hline RIFLE & Number & Percentage \\
\hline R & 10 & 17.86 \\
I & 12 & 21.43 \\
F & 6 & 10.71 \\
L & 6 & 10.71 \\
E & 22 & 39.29 \\
Total & $\mathbf{5 6}$ & 100.00 \\
\hline
\end{tabular}

\section{Conclusion}

Acute kidney failure is a common obstetric complication. All types of acute kidney failure were observed with a predominance of functional IRA. Early management by a multi-displiary team would prevent maternal and fetal complications.

\section{Conflicts of Interest}

The authors declare no conflicts of interest regarding the publication of this paper.

\section{References}

[1] Mohamed, M., Salmi, S., Musaid, I. and Benyounes, B. (2011) Acute Renal Failure 
Requiring Haemodialysis in Obstetrics. Néphrologie \& Thérapeutique, 7, 178-181. https://doi.org/10.1016/j.nephro.2010.12.003

[2] Gopalakrishnan, N., Dhanapriya, J., Muthukumar, P., et al. (2015) Acute Kidney Injury in Pregnancy-A Single Center Experience. Renal Failure, 37, 1476-1480. https://doi.org/10.3109/0886022X.2015.1074493

[3] Jim, B. and Garovic, V.D. (2017) Acute Kidney Injury in Pregnancy. Seminars in Nephrology, 37, 378-385. https://doi.org/10.1016/j.semnephrol.2017.05.010

[4] Liu, Y.-M., Bao, H.-D., Jiang, Z.-Z., Huang, Y.-J. and Wang, N.-S. (2015) Pregnancy-Related Acute Kidney Injury and a Review of the Literature in China. Internal Medicine, 54, 1695-1703. https://doi.org/10.2169/internalmedicine.54.3870

[5] Lopes, J.A. and Jorge, S. (2013) The RIFLE and AKIN Classifications for Acute Kidney Injury: A Critical and Comprehensive Review. Clinical Kidney Journal, 6, 8-14. https://doi.org/10.1093/ckj/sfs160

[6] Diouf, A.A., Diallo, M., Mbaye, M., Diarra Sarr, S., Ma Edouard Faye-Dieme, J.C. and Moreau, A.D. (2013) Epidemiological Profile and Management of Eclampsia in Senegal: About 62 Cases. Pan African Medical Journal, 16, 83. https://doi.org/10.11604/pamj.2013.16.83.3101

[7] Prakash, J., Pant, P., Prakash, S., Sivasankar, M., Vohra, R., Doley, P.K., et al. (2016) Changing Picture of Acute Kidney Injury in Pregnancy: Study of 259 Boxes over a Period of 33 Years. Indian Journal of Nephrology, 26, 262-267. https://doi.org/10.4103/0971-4065.161018

[8] Alaoui, S., Alaoui, F., ChemLal, A., Haddiya, I., Brahim, H. and Bentata, Y. (2016) Acute Obstetric Renal Failure: Renal and General Prognosis. Nephrology \& Therapeutics, 12, 344. https://doi.org/10.1016/j.nephro.2016.07.164

[9] Lemrabott, A.T., Mah, S.M., Faye, M., Saleck, M., Cisse, M.M., Fall, K. and Ka, E.H.F. (2017) Acute Postpartum Renal Failure in Mauritania: Prevalence, Etiologies and Prognostic Factors. Nephrology \& Therapeutics, 13, 365. https://doi.org/10.1016/j.nephro.2017.08.230

[10] Eswarappa, M., Madhyastha, P.R., Puri, S., Varma, V., Bhandari, A. and Chennabassappa, G. (2016) Postpartum Acute Kidney Injury: A Review of 99 Cases. Renal Failure, 38, 889-893. https://doi.org/10.3109/0886022X.2016.1164015

[11] Tondi, Z.M.M. (2016) Acute Renal Failure Obstetric: Maternity Experience Issaka GAZOBY from Niamey (Niger). European Scientific Journal, 12, 281-289. https://doi.org/10.19044/esj.2016.v12n33p281 